\title{
Letter to the editor: Impact of the EPISCISSORS-60 mediolateral episiotomy scissors on obstetric anal sphincter injuries: a 2-year data review in the United Kingdom
}

\author{
Firouzeh Sheikhi $^{1} \cdot$ Roksana Janghorban $^{2} \cdot$ Fatemeh Azarkish $^{1,3}$ CD \\ Received: 18 November 2020 / Accepted: 2 December 2020 / Published online: 21 January 2021 \\ (C) The International Urogynecological Association 2021
}

We had the great pleasure of reading the article titled "Impact of the EPISCISSORS-60 mediolateral episiotomy scissors on obstetric anal sphincter injuries: a 2-year data review in the United Kingdom" written by Koh et al. [1]. We congratulate the authors for choosing this theme. The article addresses the sustained reduction in OASIS rates associated with using EPISCISSORS-60®. However, we want to make a few points. It was better to compare confounding factors such as a prolonged second stage of labor, operative assisted vaginal births, maternal and neonatal characteristics and race [2] in the study of 2014 and 2016-2017.

The use of episiotomy for the prevention of OASIS is not routinely recommended $[3,4]$. It seems that the increase in episiotomy (29\% vs $33.7 \%$ ) [1] in nulliparous women can be the reason for the causal decrease in obstetric anal sphincter injuries (OASIS) [5], and the causal decrease can not be simply attributed to the use of PISCISSORS60. In other words, the causal reduction OASIS can be due

Fatemeh Azarkish

dr.azarkish@irshums.ac.ir; Azarkish2005@yahoo.com

Firouzeh Sheikhi

f_sheikhi12@yahoo.com

Roksana Janghorban

Janghorban@sums.ac.ir

1 Department of Midwifery, Iranshahr University of Medical Sciences, Iranshahr, Iran

2 Department of Midwifery, School of Nursing and Midwifery, Maternal-Fetal Medicine Research Center, Shiraz University of Medical Sciences, Shiraz, Iran

3 Tropical and Communicable Diseases Research Center, Iranshahr University of Medical Sciences, Iranshahr, Iran to the increased use of episiotomy incisions by clinicians and midwives with ordinary scissors or EPISCISSORS60.Therefore, it is better to judge EPISCISSORS-60's performance in the causal reduction of OASIS by randomized controlled trial studies.

\section{Conflict of interest}

The authors declare that they have no conflict of interest.

\section{References}

1. Koh LM, van Roon Y, Pradhan A, Pathak S. Impact of the EPISCISSORS-60 mediolateral episiotomy scissors on obstetric anal sphincter injuries: a 2-year data review in the United Kingdom. Int Urogynecol J. 2020. https://doi.org/10.1007/s00192019-04201-7.

2. Kimmich N, Birri J, Zimmermann R, Kreft M. Prediction of levator ani muscle avulsion by genital tears after vaginal birth - a prospective observational cohort study. Int Urogynecol J. 2020;31(11): 2361-6.

3. de Vogel J, Van Der Leeuw-Van Beek A, Gietelink D, Vujkovic M, de Leeuw JW, van Bavel J, et al. The effect of a mediolateral episiotomy during operative vaginal delivery on the risk of developing obstetrical anal sphincter injuries. Am J Obstet Gynecol. 2012;206(5):404. e1-e5.

4. Jiang H, Qian X, Carroli G, Garner P. Selective versus routine use of episiotomy for vaginal birth. Cochrane Database Syst Rev. 2017;2(2):CD000081.

5. Zhao B, Chen Y, Xi F, Dong T, Pu Y, Wang Y, et al. Training effect on performance of mediolateral episiotomies for obstetricians and midwives. 2020. https://doi.org/10.21203/rs.2.20044/v1.

Publisher's note Springer Nature remains neutral with regard to jurisdictional claims in published maps and institutional affiliations. 